\title{
Os impactos gerados pela greve dos caminhoneiros no Brasil e a resiliência nos equipamentos e serviços turísticos
}

\author{
The Impacts Generated by the Truck Drivers Strike in Brazil and the Resilience in \\ Tourism Equipments and Services
}

\section{Los impactos generados por la greve de los camioneros en Brasil y la resiliencia en los equipos y servicios turísticos}

\author{
Amanda Souza Lopes ${ }^{1}$ \\ Jaqueline Danielle Santos Correa ${ }^{2}$ \\ Thais Coratini da Silva ${ }^{3}$ \\ Ylana Silva Rodrigues ${ }^{4}$
}

\begin{abstract}
Resumo: O setor de turismo no Brasil sofreu impactos inesperados devido ao cenário do movimento de greve dos caminhoneiros, cuja funcionalidade agrega aspectos importantes na distribuição de recursos para o perfeito desempenho da atividade turística. Este artigo tem por objetivo relatar os impactos do movimento dos caminhoneiros e as consequências na dimensão do turismo. Além disso, apresentar conceitos sobre resiliência organizacional e como as firmas devem se portar a eventos disruptivos. A busca bibliográfica baseia-se em plataformas jornalísticas, artigos, sites institucionais e/ou governamentais. Por fim, a crise econômica gerada pela greve de caminhoneiros reafirmou interdependência do setor de transporte a atividade turística, esta última, quando apoiada a dinâmica da resiliência desenvolve respostas inovadoras em rápida temporalidade.
\end{abstract}

Palavras-chave: Turismo; greve; resiliência; organização; transporte.

Abstract: The tourism sector in Brazil has suffered unexpected impacts due to the scenario of the truckers strike, whose functionality adds important aspects in the distribution of resources for the perfect performance of the tourist activity. This article aims to report the impacts of the truck drivers movement and the consequences on the tourism dimension. In addition, present concepts about organizational resilience and how firms should engage in disruptive events. The bibliographic search is based on journalistic platforms, articles, institutional and / or governmental websites. Finally, the economic crisis resulted by the truck drivers' strike reaffirmed the interdependence of the transport sector to tourism activity, this one, when supported by the dynamics of resilience develops innovative responses in a timely manner.

Keywords: Tourism; strike; resilience; organization; transport .

Resumen: El sector de turismo en Brasil sufrió impactos inesperados debido al escenario del movimiento de huelga de camioneros, cuya funcionalidad agrega aspectos importantes en distribución de recursos para el perfecto desempeño del actividad turística. Este artículo

\footnotetext{
${ }^{1}$ Graduação, Bacharel em Turismo - Universidade de Brasília. E-mail: lopes0605@gmail.com Orcid: https://orcid.org/0000-0003-2967-2890

${ }^{2}$ Graduação, Bacharel em Turismo - Universidade de Brasília. E-mail: jaquelinedscorrea@hotmail.com Orcid: https://orcid.org/0000-0002-1701-4797

${ }^{3}$ Graduação, Bacharel em Turismo - Universidade de Brasília. E-mail: thaissilva1136@gmail.com Orcid: https://orcid.org/0000-0003-1808-0216

${ }^{4}$ Graduação, Bacharel em Turismo - Universidade de Brasília. E-mail: ylanasilvarodrigues@gmail.com Orcid: https://orcid.org/0000-0001-7539-6482
} 
tiene por objetivo relatar los impactos del movimiento de camioneros y las consecuencias en la dimensión del turismo. Allende, presentar conceptos sobre resiliencia organizacional e cómo las firmas deben comportarse a eventos disruptivos. La busca bibliográfica se basa en plataformas periodísticas, artículos, sitios institucionales y/o gubernamentales. Por final, la crisis económica generada por la huelga de camioneros reafirmó interdependencia del sector de transporte a actividad turística, esta última, cuando apoyada la dinámica de la resiliencia desarrolla respuestas innovadoras en rápida temporalidad.

Palabras clave: Turismo; Huelga; Resiliencia; Organización; Transporte.

\section{Introdução}

O turismo é um fenômeno que se estabelece em muitos lugares no mundo como um importante fator econômico, e seu desenvolvimento se destaca em agências de viagens, aeroportos, hotelarias, cidades, entre outros. O setor operacional de turismo contribui para o progresso de gerenciamento e planejamento turístico em âmbito regional e local, podendo contribuir para o desenvolvimento econômico, social, ambiental e cultural no ambiente em que se insere. Em casos de eventos inesperados nessas dimensões, podem ocasionar desequilíbrios, onde a resiliência vem a se tornar uma ferramenta de grande importância.

O turismo resiliente vem dos princípios de sustentabilidade e responsabilidade LANZARINI \& BARRETTO (2014), e para poder agir com resiliência os profissionais da área necessitam ampliar seus conhecimentos através de um planejamento de turismo responsável. De acordo com BENI (2006) o planejamento turístico deve ser efetuado através de um diagnóstico de forma sustentável em que se leva em consideração a prevenção de possíveis impactos. Porém, atualmente muitos impactos ocasionados pelo turismo são relacionados à falta de profissionalismo ou conhecimento sobre o tema e, assim quando ocorrem mudanças ligadas às crises, fica cada vez mais visível que a resiliência merece um lugar em todas as áreas de profissionalização.

A resiliência é uma estratégia de segurança e força nas atuações de planejamento e gerenciamento turístico em que é preciso resistir, enfrentar, se adaptar ou superar determinados impactos das mudanças provenientes de uma ocorrência. A resiliência Organizacional, que é destacada neste artigo, se apresenta como a capacidade de uma organização, instituição ou pessoa, antecipar, preparar, ou adaptar-se à transformações graduais e, interrupções causadas por algum evento inesperado. Essa resiliência é uma estratégia para uma organização prosperar no mundo com uma visão mais dinâmica e conectada à atualidade. Se trata de um exercício a ser obtido a longo prazo, SOBRARE (2018). Quando se passa por isso, é preciso que as organizações saibam dominar a resiliência organizacional no que se refere à adoção de hábitos de excelência, e melhores práticas a fim de promover a melhoria nos negócios, e capacidades em todos os aspectos de uma organização. Isto permite aos líderes assumir os riscos com confiança. 
No primeiro semestre de 2018 ocorreu um evento de grande impacto no Brasil - a greve dos caminhoneiros - sendo a causa de uma situação desconfortável para a economia brasileira. De acordo com a reportagem apresentada no site da Transporte Press (2018) A greve, foi uma paralisação de caminhoneiros autônomos com extensão nacional iniciada no dia 21 de maio, no Brasil, durante o governo de Michel Temer. Os grevistas se manifestaram contra os reajustes frequentes e sem previsibilidade mínima nos preços dos combustíveis. A greve teve como consequência muitos desdobramentos na sociedade, o que resultou de dificuldades e momentos de resiliência no mercado de Turismo no Brasil.

Nos dias de greve, o setor de Turismo vivenciou situações de apertos. A greve ocorrida fez com que o mercado de aviação perdesse milhões em voos cancelados devido ao desabastecimento dos combustíveis aéreos. Nos hotéis, as reservas de hospedagem também caíram, bares e áreas de lazer foram fechados e o cancelamento de eventos também reagiram aos impactos negativos no âmbito turístico, tendo em vista que ocorria em época festiva de Copa do Mundo.

O Conselho de Turismo da Fecomércio Federação do Comércio de Bens, Serviços e Turismo (2018) do Estado de São Paulo estimou que o setor de turismo na capital paulista acarretou perda de $\mathrm{R} \$ 104$ milhões no faturamento com a paralisação dos caminhoneiros. $A$ estimativa foi baseada nos dados da PCSS Pesquisa Conjuntural do Setor de Serviços da associação, com a análise do Grupo 13, que envolveu as atividades de hotelaria, agências de turismo, excursões, planejamento e organização de feiras, festas e congressos.

Um levantamento realizado com associadas ao SINFRET (2018) Sindicato das Empresas de Transporte de Passageiros por Fretamento do Estado de São Paulo, que representa as empresas do setor na região do $A B C$ Paulista, mostrou os impactos da greve dos caminhoneiros nessas empresas. Entre os prejuízos constatados, o levantamento registrou empresas que tiveram $40 \%$ das viagens canceladas pelos clientes, que não possuíam matéria-prima ou demais componentes fabris para que seus funcionários continuassem trabalhando.

No que diz respeito ao abastecimento, outras empresas do setor tiveram prejuízo de quase $20 \%$ comprando diesel diretamente nos postos, ou seja, pagando o preço da bomba. Em semana de feriado prolongado, também houve casos de empresas que registraram $30 \%$ das viagens de turismo canceladas. Para algumas empresas do setor, os impactos da greve dos caminhoneiros acarretaram prejuízo de mais de $25 \%$ no mês em relação ao faturamento dessas viagens eventuais. Neste processo, a resiliência organizacional surge como um fator significativo para o sucesso e sustentação da mudança pretendida. SINFRET (2018, s/p).

O objetivo deste estudo é apresentar os impactos do movimento dos caminhoneiros mediante a greve e as consequências na dimensão do turismo. Apurando o cenário histórico 
e aspectos relevantes a paralisação; além de analisar o setor do turismo e quais foram as alternativas imediatas propostas para sanar os imprevistos.

A Pesquisa foi realizada bibliográfica e eletronicamente, em capítulos de livros, sites institucionais e governamentais, artigos encontrados em sistemas de indexação, pesquisa e disponibilização gratuita de produção científica, particularmente o Spell e Capes, com palavras-chave: Resiliência, Turismo, Resiliência Organizacional, Profissional, Planejamento, Econômico, Social, Cultural, Negócios, Trabalho, Combustíveis, Caminhoneiros, Greve, Impactos, Hotelaria, Alimentos e Bebidas, Transporte. Foram utilizados, também, matérias jornalísticas eletrônicas do período que antecedeu a greve, durante e após seu término, dos jornais G1, O Globo, Valor, EIPais, Hotel News, BBC News, Catraca Livre e HotelierNews, e estes, pesquisados no período que compreende ao mês de Novembro de 2018.

O Estudo está estruturado por breve discussão sobre Resiliência organizacional nos equipamentos e suporte ao turismo; A greve; Análise dos impactos causados pela greve nos equipamentos turísticos; O transporte na cadeia de suprimentos no Brasil; seguido de sucinta conclusão sobre a discussão iniciada.

\section{Resiliência organizacional nos equipamentos e suporte ao turismo}

Em uma reportagem na plataforma PANROTAS (2018), a diretora da WTM Latin America, Luciane Leite, afirma que os seis primeiros meses do ano foram marcados por dois fatores, sendo um já aguardado, a Copa do Mundo, e um imprevisto, a greve dos caminhoneiros.

Segundo LEITE (2018):

"A proximidade com que os eventos se desenrolaram gerou um efeito cascata por todo o país. Durante os dias de greve, o setor de Turismo vivenciou uma série de reveses. A aviação, por exemplo, perdeu milhões em voos cancelados devido ao desabastecimento dos combustíveis. Os hotéis viram suas ocupações e reservas de hospedagem caírem abruptamente, o cancelamento dos eventos corporativos também impactou negativamente o âmbito turístico afetando a cadeia como um todo". (LEITE,2018, s/p)

De acordo com a reportagem os hotéis tiveram reservas de hospedagem canceladas, os eventos corporativos também tiveram impactos negativos e em todo âmbito turístico. Em momento de copa do mundo a queda da produtividade contribuiu para com uma estagnação em que afastou viajantes de suas viagens internacionais. porém, os impactos em viagens internas e de pouca duração foram menores.

"Um levantamento da Associação Brasileira da Indústria de Hotéis $(\mathrm{ABIH})$ registrou a retomada do mercado após queda de quase $30 \%$ 
na ocupação nacional. Já nas viagens aéreas, houve companhia área que disponibilizou mais de 1,6 mil voos extras para a temporada de 1 a 31 de julho, com concentração maior das operações adicionais partindo de São Paulo, Salvador, Recife, Porto Alegre, Rio de Janeiro e Fortaleza". LEITE (2018, s/p)

Apesar do ocorrido, LEITE (2018) diz que os serviços de turismo está mais cauteloso mas os profissionais que atuam neste segmento tem muitas possibilidades de gerar riqueza, renda e emprego, e cabe a resiliência para inovar e construir relações e oportunidades que trarão ao mercado de Turismo ainda mais maturidade e crescimento.

A resiliência, quando aprofundada nos termos de organizações apresenta que pessoas tendem a serem resilientes quando estão diante de estresse ou adversidades em seu desempenho profissional e que esse comportamento resiliente pode ser melhor desenvolvido em possíveis situações semelhantes.

"Resiliência é um comportamento diante de adversidades e não uma característica permanente de personalidade, isto é, não se é resiliente como características geral, mas existe o potencial de ter comportamentos adequados diante de diferentes vulnerabilidades". SOBRARE (2018). Assim, no turismo veremos suas atuações e flexibilidades organizacionais no momento da Greve dos Caminhoneiros no Brasil e como isso afetou os serviços de turisticos.

Baseando-se no conceito de resiliência já apresentado neste documento, tendo em consideração os empreendimentos e organizações inteiramente ligada a situações inesperadas submetido a processos de adaptação, é resiliente aquele que consegue enfrentar situações adversas, por exemplo, quando gera inovação tecnológica, gerando capacidade de superação por meio de novos modelos bem sucedidos.

A resiliência organizacional é necessária, e a Inovação Radical é um dos conceitos relevantes nesta discussão, que tem como objetivo principal o redesenho tecnológico:

"Inovação radical em tecnologia, já traz a idéia de ruptura e adaptação positiva do grupo organizacional em um novo patamar de complexidade, após o redesenho das formas de trabalho, do modelo de negócios, dos produtos e/ou serviços que acompanham a inovação radical em tecnologia.". ( VASCONCELOS, 2017, p. 164)

A estabilidade da organização impõe inovação que facilmente se adapte a mudanças imprevisíveis. Neste caso, se tratando do rompimento causado por crises econômicas ou política, como exemplo, a greve dos caminhoneiros. Assim, as capacidades dessa inovação depende da empresa, pois uma empresa que inova, aprimorar suas competências frequentemente, sendo elas internas ou externas, será de grande importância para as ocorrências futuras.

\section{A Greve}


A greve dos caminhoneiros iniciou no dia 21 de maio de 2018,e durante 10 dias interrompeu rodovias em pelo menos 24 estados, impactando o país com a falta de insumos por conta da logística de transporte terrestre.

Uma das principais reivindicações era a diminuição do preço do combustível, inclusive com a diminuição de impostos sobre estes, já que desde 2016, a Petrobras tem o aumento do dólar e do petróleo internacional como base para a sua política de preços e em 2017, seu site institucional, a estatal declarou a decisão de que os ajustes nos preços dos combustíveis, de mensais, ocorreriam a qualquer momento, inclusive diariamente, dentro de uma faixa determinada, de redução de $7 \%$ a alta de $7 \%$, com objetivo de gerar receita e recuperar competitividade no mercado. Outra exigência seria a fixação de uma tabela mínima para os valores de fretes, pois de 2001 a 20016, a frota de caminhões cresceu 84\%, e todo esse excesso, somado a redução de circulação de cargas, derrubou o preços dos fretes.

No dia 14 de Maio, a Associação Brasileira de Caminhoneiros (Abcam) protocolou oficio ao presidente, Michel Temer, onde exigia a baixa do preço dos combustíveis, com prazo para negociações até dia 20 de maio, caso contrário, a categoria entraria em greve em nível nacional.

A BBC News (2018) dedicou matéria à greve e as ações do poder público empreendidas para resolver o conflito, e por ela tomaremos base para descrever cronologicamente.

No dia 21 de maio a greve se iniciou com a adesão de 17 estados, e no dia seguinte, 24 estados. Ainda segundo o jornal, no dia 23, a Petrobras anuncia a redução de $10 \%$ do preço do diesel nas refinarias por 15 dias, congelando os preços nesse período.

No dia seguinte, "os efeitos (...) incluem redução de frotas de ônibus, falta de combustíveis e disparada de preços em postos de gasolina, cancelamento de aulas em universidades, voos ameaçados por falta de combustível, prateleiras vazias em supermercados e centros de abastecimento e a interrupção da produção em fábricas" BBC NEWS (2018). Nesse momento, o discurso anticorrupção entra cena, inclusive com apoio à "intervenção militar" . Logo em seguida, o governo federal anuncia acordo com representantes da categoria para a suspensão da greve, se comprometendo a atender 12 das reivindicações. Porém, muitos caminhoneiros não reconhecem esse acordo e a greve continua.

Nesse momento a Polícia Federal anuncia o início de investigações sobre a suspeita de que empresas do setor estariam influenciando ou apoiando a paralisação, uma prática proibida na legislação brasileira. Ocorre o reforço à Polícia Rodoviária Federal na liberação de estradas com a Força Nacional e, no dia 25, o, Michel Temer, anuncia a publicação de 
decreto dando poder de polícia às forças armadas até o dia 04 de Junho, denominado operação GLO (de Garantia da Lei e da Ordem), a missão seria garantir a distribuição de combustíveis nos pontos críticos, escoltar comboios, proteger infraestruturas e desobstruir vias próximas às refinarias, inclusive o Governo poderia "requisitar" temporariamente os caminhões parados. À noite, o Supremo Tribunal Federal (STF) deu aval para a remoção de manifestantes, assim como a aplicação de multas para os que bloqueassem ou manifestassem nas vias e para entidades organizadoras do movimento.

No sábado do dia 26 , segundo o governo, a situação começa a se normalizar, com a desobstrução de vias e reabastecimento em aeroportos acontecendo, mas ainda sem prazo para o abastecimento voltar ao normal. Dia 27, a ABCAM assina acordo com o Governo Federal, e, afirmando que foram atendidos em diversas reivindicações, pede para que a categoria volte ao trabalho. Porém, a paralisação continua.

No dia 29, a greve perde força, segundo a PRF, o número de protestos aumentou, porém o de caminhões parados havia diminuído, e o abastecimento nos postos de combustíveis e aeroportos começava a se normalizar. Nesse momento, Procons e Agência Nacional de Petróleo, Gás Natural e Biocombustíveis (ANP) registraram queixas em pelo menos 22 estado e no Distrito Federal, sobre reajustes "abusivos" de estabelecimento diante da escassez, levando os órgãos de defesa do consumidor intensificaram fiscalizações, aplicar multas e até interditar estabelecimentos.

No dia 30 de Novembro, praticamente todos os pontos de concentração de caminhoneiros já haviam sido eliminados pela PRF e Forças armadas, assim como a normalização de abastecimento em postos de combustíveis, porém em algumas áreas ainda a necessidade de escolta ou de decisões judiciais, havendo casos de grandes filas para abastecer, incerteza sobre estoque, assim como contingenciamento por parte das distribuidoras.

\section{Análise dos impactos causados pela greve nos equipamentos turísticos}

\section{Hotelaria}

Segundo Amazonas e Abreu (2018), no dia 29 de maio de 2018, o presidente Michel Temer afirmou que o governo já se utilizou de todos os recursos para atender às demandas reivindicadas na greve dos caminhoneiros, classe que já está estava em protesto pelo 10은 dia consecutivo. Em entrevista ao programa Cenário Econômico, da TV Brasil, Temer reforçou que acredita no fim das paralisações até o fim do dia 30 de maio, segundo dados divulgados pela Agência Brasil. Apesar do cenário ainda caótico que afetou diversos setores da indústria no Brasil todo, a situação aparentou se normalizar aos poucos. 
De acordo com Alexandre Sampaio (2018) - presidente da Federação Brasileira de Hospedagem e Alimentação (FBHA) - e do conselho da Confederação Nacional do Comércio de Bens, Serviços e Turismo (CNC), o quadro estava dramático. De acordo com ele, nos destinos próximos a capitais, que são acessíveis por veículos terrestres, os cancelamentos oscilaram entre $10 \%$ e $20 \%$.

"Tivemos muitos registros de cancelamentos na véspera do feriado, principalmente em Gramado (RS), na região Serrana do Rio de Janeiro (RJ), em Campos do Jordão (SP) e em outros lugares de destinação próximos à capital paulista. $O$ mesmo se deu em relação ao litoral paranaense e em alguns locais próximos a Salvador (BA), e em roteiros de águas termais, em Minas Gerais".

Entretanto, mesmo cidades maiores, como é o caso da capital fluminense, tiveram uma média de $15 \%$ de desistência. "Muitos turistas ficaram com medo de chegarem ao local e não conseguirem alugar um carro", de acordo com Alexandre Sampaio.

No caso dos resorts, Alberto Cestrone, presidente da Associação Brasileira de Resorts (ABR), reforçou que o Nordeste sofreu menos com os impactos, enquanto as regiões Sul e Sudeste tiveram mais problemas. Apesar do alarmismo, segundo ele, o segmento não foi tão afetado pelo transporte aéreo. "No início, as notícias criaram um pouco de dúvidas, mas no final isto não gerou muitos problemas", ressalta.

Orlando de Souza (2018), presidente executivo do Fórum de Operadores Hoteleiros do Brasil (FOHB), apontou três problemas causados pela greve. "Foi necessário criar planos de contingência em relação aos funcionários, entre hotéis de uma mesma rede para suprir uma eventual falta de produtos, e também aos cancelamentos de reservas". Segundo o executivo, houve relatos de empreendimentos que solicitaram a colaboradores que pernoitaram no hotel para garantir mão de obra suficiente para suprir os serviços, como arrumação dos quartos e café da manhã.

Os hotéis de Porto de Galinhas, em Pernambuco, segundo a revista Hotel News, em geral não foram afetados pelos cancelamentos. Porém, tiveram que gastar mais com a energia. De acordo com Brenda Silveira, diretora executiva do Convention \& Visitors Bureau de Porto de Galinhas, os empreendimentos do destino têm um acordo com a Companhia Energética de Pernambuco e utilizam geradores em horários de picos para diminuir os gastos - para ambos. "Com a falta de diesel foi necessário utilizar apenas energia elétrica e isso irá impactar na conta no próximo mês. Estamos tentando encontrar uma forma de diminuir esse valor", afirmou Brenda. Os empreendimentos também foram impactados com o abastecimento de alguns produtos, principalmente alimentos, além de terem que fornecer meios para os funcionários chegarem ao trabalho.

\section{A\&B - Alimentos e Bebidas}


Segundo Villas (2018), após os três dias de greve, o abastecimento de alimentos na maior capital do país sofreu seus primeiros impactos. Em São Paulo, na Ceagesp (Companhia de Entrepostos e Armazéns Gerais de São Paulo), maior entreposto de frutas, verduras e legumes do Brasil, houve queda na entrada de produtos de outros Estados, com consequente aumento dos preços.

Segundo Flávio Godas, economista do Centro de Abastecimento, os atacadistas chegaram a antecipar as entregas de segunda feira para domingo, já cientes da possível paralisação dos caminhoneiros. Entre as principais altas diárias foram: a do mamão (18,4\%), do melão $(10,4 \%)$ e da manga (2,7\%). No caso do mamão formosa, os preços já vinham em alta devido a problemas climáticos e queda da oferta no Rio Grande do Norte e Espírito Santo.

Outro produto fortemente impactado em disponibilidade e preço foi a batata, cuja oferta está atualmente concentrada em Minas Gerais e do Paraná. O produto apresentou preço médio de $\mathrm{R} \$ 3,03$ o quilo na Ceagesp no dia 23 de maio de 2018 , valorização de $33,4 \%$.

Segundo o mesmo jornal, mesmo com o impacto da paralisação dos caminhoneiros sobre o abastecimento de produtos in natura, as vendas de super e hipermercados cresceram 0,6\% de abril para maio de 2018.

O bloqueio de estradas por motoristas do transporte de cargas teve início em 21 de maio e durou 11 dias. No período da mobilização, o abastecimento de produtos hortifrutigranjeiros em supermercados foi um dos mais afetados, por serem perecíveis, como frutas e legumes. Isso chegou a provocar aumento de preços desses produtos no comércio, como sinalizou o Índice Nacional de Preços ao Consumidor Amplo (IPCA).

Segundo Isabella Nunes (2018) - gerente da Coordenação de Serviços e Comércio do IBGE - os consumidores provavelmente substituíram esses produtos in natura nos supermercados por alimentos industrializados, menos impactados pela crise de desabastecimento, compensando a receita dos estabelecimentos comerciais. Segundo Isabella, "Os estoques de industrializados são refeitos de 15 em 15 dias.

Isabella lembra ainda que os supermercados vendem itens de primeira necessidade. Portanto, mesmo com a dificuldade de circulação das pessoas por causa da escassez de combustíveis nas cidades, o deslocamento para compras de alimentos foi priorizado. "Famílias também compraram mais, para guardar produtos durante a greve, o que pode ter ajudado", disse ela.

Isso não significa, porém, que as vendas de hiper e supermercados não tenham sido influenciadas em nada pelas manifestações. O ritmo de vendas do setor perde fôlego em 
relação a abril, quando havia crescido $2 \%$ em comparação a fevereiro. "Todos os setores perderam fôlego em maio", disse Isabella.

\section{Transportes}

Segundo o site G1 Globo, no segundo dia de paralisação dos caminhoneiros, que protestavam contra a alta dos preços do óleo diesel, o movimento teve a adesão de mais profissionais e o número de interdições somente em rodovias federais chegou a 275 pontos segundo dados da Polícia Rodoviária Federal (PRF). De acordo com a Associação Brasileira dos Caminhoneiros (Abcam) a adesão ao protesto subiu de 200 mil para mais de 300 mil profissionais. O aumento das adesões e dos pontos de interdição afetou o abastecimento e o funcionamento do setor de alimentos, transportes e das empresas.

Em seu quarto dia, a greve dos caminhoneiros afetou o transporte público de diversas cidades do Brasil. Por causa da dificuldade no abastecimento de combustível, as empresas reduziram o número de ônibus em circulação. Os impactos da greve foram sentidos em outros setores econômicos. Além da falta de gasolina, há relatos de desabastecimento de alimentos, especialmente de produtos como frutas, verduras e legumes. Desde segunda-feira, 21 de maio de 2018, caminhoneiros bloquearam as principais estradas do país em protesto contra o aumento nos preços dos combustíveis e pediam ao governo a redução de impostos.

Prejudicada pela greve dos caminhoneiros, a economia brasileira sofreu uma contração de 3,34\% em maio, mostrou o Índice de Atividade Econômica do Banco Central (IBC-Br), considerado uma "prévia" do resultado do Produto Interno Bruto (PIB). Outros indicadores de maio já haviam apontado a dimensão do estrago. O desempenho dos serviços mostrou um dos principais danos na economia causados pela greve. O setor, que tem peso importante no PIB, caiu $3,8 \%$ no mês da paralisação. Economistas e o próprio governo já esperavam menor crescimento no ano e retomada mais difícil.

\footnotetext{
"As vendas do comércio varejista brasileiro caíram $0,6 \%$ em maio na comparação com abril. Foi a primeira queda registrada neste ano. Todas as atividades do comércio tiveram perdas em maio, à exceção de hipermercados e supermercados. O desempenho de maio praticamente anulou o avanço de $0,7 \%$ observado em abril", segundo publicado no site (G1,13 de Jul. de 2018)
}

No Recife, em horário de pico, das $5 \mathrm{~h}$ às $8 \mathrm{~h}$, a circulação dos ônibus foi reduzida de 10\% a 30\%, segundo o órgão gestor, a Grande Recife Consórcio de Transporte. O consórcio autorizou as empresas a reduzir a circulação de metade dos veículos fora do horário de pico, $8 \mathrm{~h}$ às $17 \mathrm{~h}$, para economizar combustível, e garantir a volta dos trabalhadores para casa ao final do expediente. "Essas medidas contingenciais são uma 
tentativa de prolongar o serviço de transporte público o máximo possível, até a solução definitiva por parte do governo federal", informou o consórcio, em nota.

O sistema de transporte no estado do Rio de Janeiro operava com $67 \%$ do total da frota, informou a Fetranspor (Federação das Empresas de Transporte de Passageiros do Estado do Rio de Janeiro). No total, 7.590 coletivos deixaram de circular. Por isso, os intervalos de tempo entre as viagens eram maiores. Na capital, o BRT estava funcionando com $50 \%$ da frota. Todas as estações da avenida Cesário de Melo, nos corredores Transoeste e Transcarioca, trecho entre Madureira e Fundão, estavam fechadas.

\section{O transporte na cadeia de suprimentos no Brasil}

Segundo Ballou (2006), o transporte é o elemento mais importante dentro da cadeia de suprimentos, podendo absorver dois terços dos custos logísticos totais, e entre os custos relevantes, figuram itens como combustível, salários, manutenção, depreciação do equipamento e custos administrativos, o que leva muitas empresas optarem pelo fretamento deste serviço. Os transportes no contexto brasileiro giram em torno de cinco modais básicos: hidroviário, ferroviário, rodoviário, aeroviário e dutoviário. O transporte rodoviário é o mais utilizado para transporte de cargas, chegando a custar sete vezes mais caro que o ferroviário, e este, cerca de quatro vezes a mais que o transporte aquático ou via dutos.

Em comparação aos outros modais, o transporte rodoviário tem vantagens no que se refere à sua flexibilidade e facilidade de acesso aos pontos de embarque e desembarque de cargas e de passageiros, door to door', sendo também o mais apropriado para transportar produtos de maior valor agregado ou perecíveis, em pequenas ou médias distâncias. Especialmente para esses casos, é mais frequente e confiável, além de possibilitar a manipulação de lotes de mercadorias de tamanhos variáveis.

A expansão rodoviária nacional se iniciou em 1944, com o Plano Rodoviário Nacional (BNDES, 1999), se expandindo rapidamente, principalmente porque, em relação à malha ferroviária, os custos de implantação por quilômetro e tempo de construção de estradas é menor, e essa expansão abriu o caminho para o surgimento de várias empresas transportadoras e profissionais autônomos, com caminhões próprios (OLIVEIRA,2004). Porém, o setor de transportes como um todo vem enfrentando grandes problemas devido à falta de planejamento e de investimentos em infra-estrutura que estabeleçam estrutura logística, para o desenvolvimento e otimizando os vários modais, de forma a reduzir os custos.

Ainda segundo Oliveira (2004), a dependência excessiva do transporte rodoviário poderia ser amenizada com o desenvolvimento e utilização dos outros modais de transporte, 
desafogando o gargalo do transporte rodoviário, reduzindo sensivelmente a maioria dos problemas causados pelo mesmo, como as más condições do asfalto, que, dependendo do estado da pista, pode haver uma aumento no consumo de combustível de até $50 \%$, dobrando-se o tempo do percurso, além do aumento do número de acidentes. Devido ao avanço tecnológico, a integração de modais diferentes se tornaria possível e efetiva dentro de uma mesma operação logística de transporte, tanto de mercadorias quanto de pessoas.

\section{Considerações finais}

Reflete-se que com esse trabalho, que a greve dos caminheiros evidenciou a enorme dependência do país ao transporte rodoviário para abastecimento de insumos e combustíveis, importantíssimos para as atividades do setor de serviços, e consequentemente o turismo.

Os serviços do setor de turismo sofreram impactos que ocorreram por conta do grande evento inesperado e essas áreas tiveram que, de imediato recorrer a resiliência ou fechar as portas de seus estabelecimentos, assim acredita-se que com essa pesquisa fica mais visível a importância da resiliência organizacional nos empreendimentos de turisticos e em todo quadro profissional da área, para que assim possam lidar com eficácias em momentos semelhantes a esse descrito.

A dinâmica da resiliência é capaz de colaborar com os processos de comunicação e organização das firmas no setor de turismo, por intermédio da tecnologia e a interação no trabalho coletivo, cujo resultados está totalmente ligado a flexibilidade que a organização tem de se adaptar e reinventar seus processos, recursos e serviços.

\section{Referências bibliográficas e eletrônicas}

BALLOU, Ronald H. Gerenciamento da Cadeia de Suprimentos / Logística Empresarial. Porto Alegre: Bookman. 2006 (Cap. 6)

VASCONCELOS, Isabella Francisca. Resiliência organizacional e teoria da ação comunicativa: Uma proposta de uma agenda de pesquisa; Revista de Administração da UNIMEP. v.15, n.4, Setembro/Dezembro de 2017.

OLIVEIRA, Simone de. Sistema de Transportes no Brasil - O Multimodalismo como Opção Logística. Orientador: MARTINS, Eduardo F. Rio de Janeiro: Universidade Gama Filho, Monografia (MBA Portos e Logística - PósGraduação Lato Sensu).2004.

BENI, Mário Carlos. Política e planejamento de turismo no Brasil. São Paulo: Aleph, 2006.

LANZARINI, R. \& BARRETTO, M. "Políticas públicas no Brasil para um turismo responsável”. Turismo: Visão e Ação, 2014. 
BBC - Greve dos caminhoneiros: a cronologia dos 10 dias que pararam o Brasil. 30 de Maio de 2018. Disponível em: <https://www.bbc.com/portuguese/brasil-44302137> Acesso em: Nov. de 2018

BNDES. Concessões Rodoviárias no Brasil. Informe Infra-Estrutura, Rio de Janeiro, Jan de 1999. Disponível em http://www.bndes.gov.br. Acesso em: Nov. de 2018.

BSIGROUP - Resiliência Organizacional [s.d.]. Disponível em: $<$ https://www.bsigroup.com/pt-BR/Nossos-servicos/Resiliencia-Organizacional/> Acesso em: Nov. de 2018

CATRACA LIVRE - Os impactos da greve dos caminhoneiros no transporte das cidades. 24 de Maio de 2018. Disponível em:<https://catracalivre.com.br/cidadania/grevecaminhoneiros-transporte-cidades/> Acesso em: Nov. de 2018

ECONOMICS - Designing Resilient, Sustainable Systems. C2003 Disponível em: $<\mathrm{http} / / /$ www.eco-nomics.com/images/Designing_Resilient_Sustainable_Systems.pdf> Acesso em: Nov.de 2018

ELPAIS - Greve dos caminhoneiros: como se formou o nó que levou à paralisação. 26 de Maio de 2018. Disponível em: <https://brasil.elpais.com/brasil/2018/05/24/economia/1527177800_693499.html> Acesso em: Nov. de 2018

G1 - Greve dos caminhoneiros provoca estragos na economia e deve dificultar retomada. 13 de Jul de 2018.Disponível em: <https://g1.globo.com/economia/noticia/greve-doscaminhoneiros-provoca-estragos-na-economia-e-deve-dificultar-retomada.ghtml> Acesso em: Nov. de 2018

HOTELIERNEWS - Impacto da paralisação dos caminhoneiros deve ser de R\$ 104 milhões no turismo de São Paulo. 30 de Maio de 2018. Disponível em: $<$ https://hoteliernews.com.br/noticias/impacto-da-paralisacao-dos-caminhoneirosdeve-ser-de-r-104-milhoes-no-turismo-de-sao-paulo-80056> Acesso em: Nov. de 2018

O GLOBO - Greve dos caminhoneiros já afeta setor de transportes, alimentação e fábricas. 22 de Maio de 2018. Disponível em: < https://oglobo.globo.com/economia/greve-doscaminhoneiros-ja-afeta-setor-de-transportes-alimentacao-fabricas-22707028 Acesso em : Nov. de 2018

REVISTA HOTELNEWS - Quais foram os reais impactos da greve dos caminhoneiros na hotelaria?. 30 de Maio de 2018. Disponível em: $<$ http://www.revistahotelnews.com.br/portal/noticia.php?id_noticia=7906>. Acesso em: Nov. de 2018.

SEGS - Impactos da greve dos caminhoneiros. 04 de Jun de 2018 Disponível em: <https://www.segs.com.br/veiculos/118938-impactos-da-greve-dos-caminhoneiros> Acesso em: Nov. de 2018.

SOBRARE - Desenvolvimento uma cultura resiliente nas organizações. C2015. Disponível em: <http://sobrare.com.br/wp-content/uploads/2015/11/ebook-desenvolvendo-umacultura-resiliente-nas-organizacoes.pdf> Acesso em: Nov. de 2018.

VALOR - Greve de caminhoneiros afeta empresas e abastecimento de combustível. 23 de Maio de 2018. Disponível em: <https://www.valor.com.br/brasil/5543695/greve-decaminhoneiros-afeta-empresas-e-abastecimento-de-combustivel> Acesso em: Nov. de 2018.

VALOR - Greve dos caminhoneiros teve impacto disseminado no varejo. 12 de Jul de 2018.Disponível em: <https://www.valor.com.br/brasil/5654435/greve-dos- 
caminhoneiros-teve-impacto-disseminado-no-varejo-nota-ibge> Acesso em: Nov. de 2018.

PETROBRAS - Revisão da política de preços de diesel e gasolina. 30 de Jun de 2017. Disponível em:<http://www.petrobras.com.br/fatos-e-dados/revisao-da-politica-deprecos-de-diesel-e-gasolina.htm> Acesso em: Jun. de 2019.

ABCAM - Ofício ABCAM No 34/2018. 14 de Maio de 2018. Disponível em:<http://www.abcam.org.br/images/OFICIO-ABCAM---N-34---PRESIDENTEMICHEL-TEMER-1.pdf> Acesso em: Jun. de 2019.

\footnotetext{
' Diferenciado processo logístico de uma mercadoria.
} 